\title{
Minimum Inhibitory Concentrations of a Broad Range of Inhibitors for the Unicellular Alga Chlamydomonas reinhardi Dangeard
}

\author{
By J. MOTTLEY* AND D. E. GRIFFITHS \\ Department of Molecular Sciences, University of Warwick, Coventry CV4 $7 A L$
}

(Received 25 May 1977)

\section{INTRODUCTION}

Determinations of the minimum concentrations of compounds which inhibit the growth of micro-organisms on solid media have several possible uses. For example, this information can be used during the isolation of drug-resistant microbial mutants, in the production and maintenance of pure cultures of micro-organisms, and in the development of rapid screening and bioassay methods for the growth inhibitors. In addition, if a micro-organism can be grown under various trophic conditions to allow the differential functioning of separate organelles, e.g. chloroplasts and mitochondria in Chlamydomonas reinhardi, then estimation of the minimum growth inhibitory concentration (m.i.c.) of an inhibitor under these conditions may give indications as to its site of action in cells.

This is a report of a study to determine the toxic levels of various types of inhibitors for $C$. reinhardi grown on solid media under different trophic conditions. This was a preparatory study to work on the isolation and characterization of drug-resistant mutants of this alga.

\section{METHODS}

Inhibitors. These were obtained from the following sources. BDH: $N, N^{\prime}$-dicyclohexylcarbodiimide (DCCD), 2,4-dinitrophenol (DNP), sodium arsenate, tetraphenylboron, rhodamines 6G and B, sodium dodecyl sulphate, trimethyltin chloride, tri-n-propyltin chloride, tri-n-butyltin chloride, triphenyltin chloride. Other organotin compounds were obtained from the Tin Research Institute, Greenford, Middlesex. Calbiochem: atractyloside, ethidium bromide, valinomycin, antimycin A, proflavin, acridine orange, carbonyl cyanide $m$-chlorophenylhydrazone (CCCP). Shell Research: aurovertin, 4,5,6,7-tetrachloro-2-trifluoromethylbenzimidazole (TTFB). Aldrich Chemical Co.: galegine sulphate, dicyclohexyl-I 8-crown-6. Pfaltz and Bauer: phlorizin. Eli Lilly: nigericin. Hopkin \& Williams: potassium cyanide. Upjohn Co.: spectinomycin. Netherlands Fermentation: Dio-9. Glaxo: venturicidin. Du Pont: '1799'. Other inhibitors were obtained from Sigma.

Minimum inhibitory concentration determinations. The $137 \mathrm{C}$ (plus mating type) strain of $C$. reinhardi was grown on the minimal/high magnesium medium of Surzycki (197I) containing I.5\% (w/v) Difco Bacto agar and either with (mixotrophic and heterotrophic growth) or without (photoautotrophic growth) the addition of $0.2 \%(\mathrm{w} / \mathrm{v})$ sodium acetate. Agar plates containing a wide range of drug concentrations were prepared by adding the drugs to autoclaved media which had been cooled to $50{ }^{\circ} \mathrm{C}$. The use of concentrated drug solutions (up to $10 \mathrm{mg} \mathrm{ml}^{-1}$ depending on the solubility of the drug) allowed unsterilized stock solutions to be used for preparing the plates. Early-stationary phase mixotrophic cultures $(72 \mathrm{~h}$ old and with a density of approximately $0.9 \mathrm{mg}$ dry $\mathrm{wt}_{\mathrm{ml}}^{-1}$ ) were applied to the plates using a multipoint inoculator (Spooner \& Sykes, 1972). The inoculated plates were incubated at $25^{\circ} \mathrm{C}$ and the extent of growth was estimated after either I week in the light at $4000 \mathrm{~lx}$ intensity (photoautotrophic and mixotrophic growth) or 2 weeks in the dark (heterotrophic growth). The sensitivity of $C$. reinhardi to each drug was assessed using a o to 2 point scale. The m.i.c. of each drug was taken as the concentration at which point I (slight trace) growth was achieved or the range between the concentrations at which point 0 (no growth) and point 2 (moderate to excellent) growth occurred.

* Present address: Chancellor College, University of Malawi, P.O. Box 280, Zomba, Malawi. 


\section{RESULTS AND DISCUSSION}

The toxic levels of various inhibitors for the growth of $C$. reinhardi on solid media are shown in Table I. The compounds are arranged in loose groupings depending on their reported biochemical modes of action in cells.

The results show that $C$. reinhardi was generally insensitive to low concentrations of many of the inhibitors although some, e.g. the triorganotins, alkylguanidines, ethidium bromide, CCCP, nigericin and cetyltrimethylammonium bromide, inhibited growth at relatively low concentrations. The increased inhibitory activity of the trialkyltins and alkylguanidines with increasing length of the alkyl substituents indicates that the toxicity of these compounds was related to their relative lipid solubilities. Heterotrophic growth was comparatively more sensitive than photoautotrophic and mixotrophic growth to a wide range of the inhibitors, including tri-n-butyltin, triphenyltin, oligomycin, Dio-9, robenzidine aurovertin, '1799', rhodamine 6G, valinomycin, dicyclohexyl-18-crown-6, antimycin A, acriflavin and acridine orange. The response of mixotrophic growth did not differ substantially from that of photoautotrophic growth except with ' 1799 ', where it was more resistant, and with trimethyltin, where it was more sensitive.

Because the cells of $C$. reinhardi have both a chloroplast and mitochondria, it is considered that heterotrophic growth of this alga is sustained by mitochondrial function only, whilst mixotrophic growth probably involves the functioning of both mitochondria and the chloroplast. Since the alga is an obligate aerobe, photoautotrophic growth should also rely on mitochondrial function but, since lesions in photosynthesis result in an inability of the cells to undergo photoautotrophic growth (Levine \& Goodenough, 1970), it would appear that photoautotrophic growth is primarily sustained through photosynthesis. Consequently, the m.i.c. of certain inhibitors for $C$. reinhardi grown under different trophic conditions may provide information about the sites of action of these inhibitors (Surzycki \& Gillham, 197I). For example, the insensitivity of the cells to KCN under mixotrophic and heterotrophic conditions may reflect the virtual absence of cytochrome $a_{3}$ in the vegetative cells of this alga (Chance \& Sager, 1957). In addition, the high sensitivity of heterotrophic growth towards antimycin A tends to confirm that the cyanide-insensitive respiration, which develops after germination of the zygospores (Hommersand \& Thimann, 1965), is due to a change in the respiratory electron transport chain at a point beyond the antimycin-sensitive $b / c_{1}$ segment found in this alga (Chance \& Sager, 1957). The toxic levels for Dio-9 correspond well with those required to inhibit whole-cell respiration and photosynthesis of C. reinhardi (Neumann \& Levine, 1971). The absence of any differential effect of rifampicin on photoautotrophic growth is surprising in view of the reported specificity of this inhibitor for chloroplast DNA transcription (Surzycki, 1969) but this may have been due to light inactivation of this light-sensitive compound.

The generally greater sensitivity of heterotrophic growth, compared with photoautotrophic and mixotrophic growth, may reflect the specific inhibition of mitochondrial function by some of the compounds. This is likely with antimycin A, oligomycin and acriflavin which are known to be more effective inhibitors of mitochondrial than of chloroplast function (Baltscheffsky, 1960; Alexander, Gillham \& Boynton, 1974). During the growth of $C$. reinhardi, the photoautotrophic medium became acidic and the mixotrophic and heterotrophic media became alkaline and these $\mathrm{pH}$ changes may have affected the toxicity of the inhibitors. However, it is unlikely that they were responsible for the heterotrophic specificity of some of the drugs since $\mathrm{pH}$ changes of the mixotrophic medium were more marked than those of the heterotrophic medium. It is possible that the slower growth of the alga in the dark, compared with growth in the light, could have contributed to the greater sensitivity of heterotrophic growth.

It should be pointed out that the assay system used in this study does not detect any differential effect of inhibitors on growth rates nor whether the inhibition is algistatic or algicidal. 
Table I. Toxic levels of various inhibitors for C. reinhardi grown on solid media under three different trophic conditions

Minimum inhibitory concentration*

Compound

Energy transfer inhibitors

Trimethyltin chloride

Triethyltin sulphate

Tri-n-propyltin chloride

Tri-n-butyltin chloride

Triphenyltin chloride

Tri-n-butyltin oxide

Tricyclohexyltin hydroxide

Octylguanidine

Dodecylguanidine

Galegine sulphate

Oligomycin

Phlorizin

Venturicidin

DCCD

Dio-9

Robenzidine

Aurovertin

Uncouplers

DNP

Atebrin

CCCP

' 1799 '

Sodium arsenate

Tetraphenylboron

TTFB
Photoautotrophic

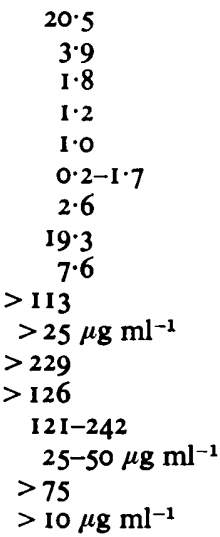

$>$ I 358

$>106$

$14 \cdot 6$

90

$>1603$

$>292$

32-79
Mixotrophic

$10 \cdot 2$

3.5

$\mathrm{I} \cdot 8$

I. 2

0.8

$\mathrm{Nr}$

2.6-26.0

$16 \cdot 9$

$7 \cdot 6$

I $3-284$

$>25 \mu \mathrm{g} \mathrm{ml}^{-1}$

$>229$

$>126$

$>242$

25-50 $\mu \mathrm{g} \mathrm{ml}^{-1}$

$>75$

$>10 \mu \mathrm{g} \mathrm{ml}^{-1}$

$\begin{aligned} &> 1358 \\ &> 106 \\ & 14 \cdot 6 \\ &> 128 \\ &> 1603 \\ &> 292 \\ & 32-79 \\ & \\ &> 119 \\ & 22-11 \mathrm{II} \\ & \\ &> 27 \\ & 7.5 \mu \mathrm{g} \mathrm{ml}^{-1} \\ &> 50 \mu \mathrm{g} \mathrm{ml}^{-1} \\ &> 269\end{aligned}$

$>3840$

$>18$

$>1105$

$>127$

$>314$

$>419$

60

$>358$

19.0

$347-694$

14-27

1449

$$
\text { 7-14 }
$$

$$
\begin{gathered}
2 \text { I-IO4 } \\
>403 \\
29-I 44 \\
>240 \\
29-I 43
\end{gathered}
$$

79

$21-104$
$>403$
$3-29$
$120-240$
$29-143$
79
$>\mathrm{I} 00 \mu \mathrm{g} \mathrm{ml}^{-1}$

Heterotrophic

$10 \cdot 2$
$3 \cdot 0$
$1 \cdot 1$
$0 \cdot 3$
$0 \cdot 1$
$<0 \cdot 2$
$0 \cdot 3-2 \cdot 6$
$14 \cdot 5$
$7 \cdot 6$
425
$10 \mu \mathrm{g} \mathrm{ml}^{-1}$
$>229$
$32-126$
$>242$
$\mathrm{I}-5 \mu \mathrm{g} \mathrm{ml}^{-1}$
$3-30$.
$\mathrm{I}-5 \mu \mathrm{g} \mathrm{ml}^{-1}$

$>$ I $35^{8}$

$>106$

8.5

51

$>1603$

$>292$

32-79

$>119$

$<22$

9

$5 \mu \mathrm{g} \mathrm{ml}^{-1}$

$>50 \mu \mathrm{g} \mathrm{ml}^{-1}$ 54

$>3840$

0
1105

$>127$

$>314$

IO $\mu \mathrm{g} \mathrm{ml}^{-1}$

140

60

287

I $2 \cdot 7$

173-347

I 208

$<7$

NT, Not tested.

- Except where indicated, these are expressed in $\mu_{\mathrm{M}}$. 
In conclusion, the low toxicity of many of the inhibitors for $C$. reinhardi means that only a few would be useful for the control or isolation of 'drug resistant mutants of this alga. Likewise, the strain of the alga used in this study would be of limited use for the bioassay of low concentrations of most of the inhibitors. However, this type of assay system may be useful during the preliminary determination of the site of action of biocides.

This work was supported by an S.R.C. postgraduate studentship to J.M.

\section{REFERENCES}

Alexander, N. J., Gillham, N. W. \& Boynton, J. E. (1974). The mitochondrial genome of Chlamydomonas: induction of minute colony mutations by acriflavin and their inheritance. Molecular and General Genetics 130, 275-290.

BALTSCHEFFSKY, H. (1960). Inhibitor studies on light-induced phosphorylation in isolated spinach chloroplasts. Acta chemica scandinavica 14, 264272.

Chance, B. \& Sager, R. (1957). Oxygen and lightinduced oxidations of cytochrome, flavoprotein and pyridine nucleotide in a Chlamydomonas mutant. Plant Physiology 32, 548-561.

Hommersand, M. H. \& ThimanN, K. V. (1965). Terminal respiration of vegetative cells and zygospores in Chlamydomonas reinhardi. Plant Physiology 40, $1220-1227$.

LeVINe, R. P. \& GoOdenough, U. W. (1970). The genetics of photosynthesis and of the chloroplast in Chlamydomonas reinhardi. Annual Review of Genetics 4, 397-408.
Neumann, J. \& LeVine, R. P. (197I). Reversible pH changes in cells of Chlamydomonas reinhardi resulting from $\mathrm{CO}_{2}$ fixation in the light and its evolution in the dark. Plant Physiology 47, 700704.

SpOONER, D. F. \& Sykes, G. (1972). Laboratory assessment of antibacterial activity. Methods in Microbiology 7B, 222-224.

SURZYCKI, S. J. (1969). Genetic functions of the chloroplast of Chlamydomonas reinhardi: effect of rifampicin on chloroplast DNA-dependent RNA polymerase. Proceedings of the National Academy of Sciences of the United States of America 63, 1327-1334.

SuRZYCKI, S. J. (1971). Synchronously grown cultures of Chlamydomonas reinhardi. Methods in Enzymology XXIIIA, 67-73.

SurzyCki, S. J. \& Gillham, N. W. (197I). Organelle mutations and their expression in Chlamy. domonas reinhardi. Proceedings of the National Academy of Sciences of the United States of America 68, I301-1306. 